University of Nebraska - Lincoln

DigitalCommons@University of Nebraska - Lincoln

U.S. Environmental Protection Agency Papers

U.S. Environmental Protection Agency

2009

Guidance on Developing Safety Performance Indicators

Kim Jennings

U.S. Environmental Protection Agency, jennings.kim@epa.gov

Francine Schulberg

$O E C D$

Follow this and additional works at: https://digitalcommons.unl.edu/usepapapers

Jennings, Kim and Schulberg, Francine, "Guidance on Developing Safety Performance Indicators" (2009).

U.S. Environmental Protection Agency Papers. 132.

https://digitalcommons.unl.edu/usepapapers/132

This Article is brought to you for free and open access by the U.S. Environmental Protection Agency at DigitalCommons@University of Nebraska - Lincoln. It has been accepted for inclusion in U.S. Environmental Protection Agency Papers by an authorized administrator of DigitalCommons@University of Nebraska - Lincoln. 


\title{
Guidance on Developing Safety Performance Indicators
}

\author{
Kim Jennings ${ }^{a}$ and Francine Schulberg ${ }^{b}$ \\ ${ }^{a}$ U.S. Environmental Protection Agency (EPA), Mailcode 5104A, 1200 Pennsylvania Avenue, NW, Washington, DC 20460 \\ and OECD Working Group on Chemical Accidents; jennings.kim@epa.gov (for correspondence) \\ ${ }^{\mathrm{b}}$ OECD Group of Experts on Safety Performance Indicators
}

Published online 17 August 2009 in Wiley InterScience (www.interscience.wiley.com). DOI 10.1002/prs.10343

This article summarizes a process for developing safety performance indicators. This is a topic of great importance for the measurement of the effectiveness of our PSM systems. The PSM is the OSHA regulation that covers companies in the United States that was issued in the year 1992. Since that time companies in the process industries have made great strides in implementing PSM systems. An important question is "How much progress have we made in actually reducing the number and severity of process events?" Other countries were also concerned about the effectiveness of their programs to address chemical accidents. In response to these concerns, the OECD published the documents described in this article.

One of these documents sets out a safety performance indicator process that allows a company to:

- assess whether it is implementing appropriate chemical safety programs and policies,

- evaluate whether these programs and policies are achieving their desired objectives, and

- help determine the extent to which such programs and policies are making a difference.

This will allow a company to identify whether there is appropriate emphasis on different aspects of safety management and provide insights needed for setting priorities for future investment of resources. (c) 2009 American Institute of Chemical Engineers Process Saf Prog 28: 362-366, 2009

Keywords: Organization for Economic Cooperation and Development, performance indicators, outcome indicators, output indicators, chemical accidents, measurement system

\section{INTRODUCTION}

In October 2008, the Organization for Economic Cooperation and Development (OECD)—an intergov-

(C) 2009 American Institute of Chemical Engineers *This is a U.S. Government work and, as such, is in the public domain in the United States of America. ernmental organization bringing together 30 countries-published Guidance on Developing Safety Performance Indicators related to Chemical Accident Prevention, Preparedness and Response [1].

The Guidance is divided into two documents, one directed to industry and the second directed at government agencies ("Public Authorities") and the Public (in particular, communities located near hazardous installations).

This Guidance was designed to allow each of the target groups to analyze their own actions, to determine whether the steps they have taken to support chemical safety are, in fact, achieving their objectives and to help identify where further action is needed. The Guidance is a companion to the OECD Guiding Principles on Chemical Accident Prevention, Preparedness and Response (2nd ed, 2003) [2].

The 2008 Guidance contains two primary components:

- a step-by-step approach for developing SPI Programs; and

- a menu of possible indicators which addresses the range of issues involved with chemical accident prevention, preparedness, and response.

This article will first provide some background information on the OECD and the value of SPI programs. It will then provide an overview of the Guidance, focusing specifically on the steps for creating an SPI Program and the menu of possible indicators. It will further describe the next steps of OECD with respect to this Guidance, which will include cooperation with CCPS.

\section{WHY OECD?}

\section{What Is the OECD?}

The Organization for Economic Cooperation and Development, established in 1961, is an organization 
of governments that are committed to democracy and a market economy. The OECD currently has 30 members ${ }^{1}$ and involves many other countries in its work.

The role of the OECD is to provide a venue for governments to compare experience, seek answers to common problems, identify good practices and, as appropriate, coordinate policies. Work is managed by specialized committees of experts from member countries (and others, as appropriate).

\section{OECD and Chemical Safety}

In 1971, OECD established a program to address chemical safety, focusing in its initial phases on chemical testing and assessment. It has expanded over time to address risk assessment and management, to share the burden of testing certain high-production volume chemicals, and to consider the safety of pesticides, biocides, and products of biotechnology. Following the Bhopal and Basle accidents, the OECD countries concluded that the program should also address the issues associated with chemical accident prevention, preparedness, and response and established a new working group to manage these activities. The Working Group on Chemical Accidents has brought together OECD and non-OECD countries, as well as industry, labor, UN bodies, and nongovernmental organizations, to cooperate in addressing issues related to chemical accident prevention, preparedness, and response. One element of its work was to develop the Guidance on Safety Performance Indicators.

\section{VALUE OF AN SPI PROGRAM}

From the perspective of industry, an SPI Program allows a company to:

- assess whether it is implementing appropriate chemical safety programs and policies,

- evaluate whether these programs and policies are achieving their desired objectives, and

- help determine the extent to which such programs and policies are making a difference.

This allows a company to identify whether there is appropriate emphasis on different aspects of safety management and provides insights needed for setting priorities for the future investment of resources.

An SPI Program can also facilitate communication and cooperation with public authorities, other enterprises, and the local community.

With respect to public authorities (government agencies), there are also a number of reasons for establishing an SPI Program, perhaps the most important being that it provides a tool to respond to the questions: what is our contribution to improved

\footnotetext{
${ }^{1}$ OECD member countries are: Australia, Austria, Belgium, Canada, the Czech Republic, Denmark, Finland, France, Germany, Greece, Hungary, Iceland, Ireland, Italy, Japan, Korea, Luxembourg, Mexico, the Netherlands, New Zealand, Norway, Poland, Portugal, the Slovak Republic, Spain, Sweden, Switzerland, Turkey, the United Kingdom, and the United States. The European Commission also takes part in the work of the OECD.
}

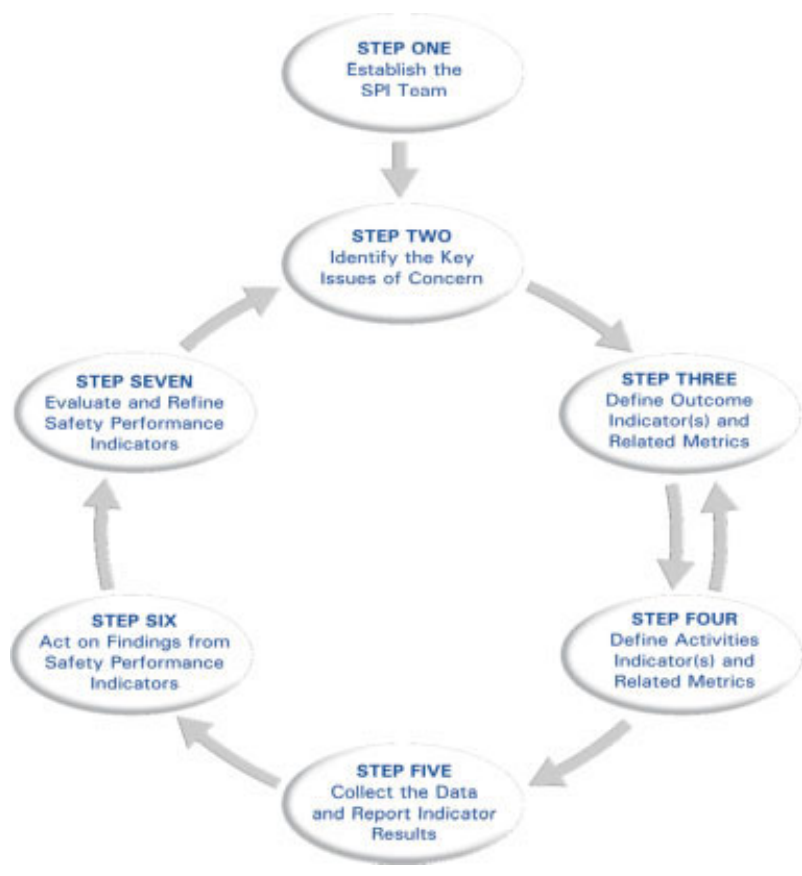

Figure 1. Seven steps to create and implement an SPI program. [Color figure can be viewed in the online issue, which is available at www.interscience. wiley.com.]

safety and are our activities leading to overall improvements? Using the output from an SPI Program, agencies can help to identify gaps in regulations and policies.

An SPI Program for government agencies also facilitates cooperation and communication with industry, communities, and others, and it may help motivate industry to improve safety. An SPI Program can help authorities to establish priorities for inspections and identify areas that should be considered during inspections and reviews.

\section{STEPS IN THE GUIDANCE FOR CREATING AN SPI PROGRAM}

The Guidance sets out a seven-step process for creating an SPI Program, i.e.:

- Step One: Establish the SPI team

- Step Two: Identify the key issues of concern

- Step Three: Define outcome indicator(s) and related metrics

- Step Four: Define activities indicator(s) and related metrics

- Step Five: Collect the data and report indicator results

- Step Six: Act on findings from SPIs

- Step Seven: Evaluate and refine SPIs

This process is illustrated in Figure 1, which shows that Steps Three and Four are generally undertaken on an iterative (rather than consecutive) basis, and showing the review cycle incorporating Steps Two to Seven. 


\section{Step One: Establish the SPI Team}

The first step in beginning the process of developing an SPI Program is to establish the team that will be involved in the development of the SPI Program. This effort should start with identifying a leader-an individual or group-who will generally oversee the Program's development, effectively communicate the efforts of the team, and promote the Program's implementation. It is also important that appropriate staff members, including technical experts and employees with hands-on knowledge, are involved in the process so the SPI Program reflects the hazards and safety measures at the facility.

Additionally, the involvement of management is critical to the success of the effort to ensure resources are committed to the Program and actions identified by the SPI Program, which are needed to improve chemical safety at the enterprise, are taken. Once the team is established, a plan should be developed which clearly identifies a timetable and milestones to ensure adequate progress is made in developing the SPI Program and appropriate resources are committed to the project.

\section{Step Two: Identify the Key Issues of Concern}

Once the SPI team and other arrangements are in place, the next step is to identify the scope of the SPI Program. Each enterprise will need to decide on its own priorities, to choose the appropriate indicators and the way they will be measured.

The scope of the Program should begin with a limited number of indicators, which can be expanded as more experience is gained in implementation. In this step, enterprises should focus on what to monitor rather than how to monitor. Additionally, enterprises should work to avoid the pitfall of measuring what they can measure instead of what they should measure.

\section{Step Three: Define Outcome Indicator(s) and Related Metrics}

In this next step, the SPI team should define outcome indicator(s) addressing the key issues of concern. Outcome indicators can help measure the extent to which a targeted safety policy, procedure, or practice is successful and is achieving the desired result. These indicators need to convey clear information on safety performance to those with the responsibility and authority to take action.

Outcome indicators are designed to collect data and provide results to help you answer the broad question of whether you have achieved a desired result but, unlike activities indicators, do not tell you why the result was achieved or why it was not.

Indicators-both outcome and activities-consist of two key components:

- A definition, which should clearly state what is being measured in terms that are meaningful to the intended audience;

- A metric, which defines the unit of measurement. This should be precise enough to highlight trends in safety over time and/or highlight deviations from safety expectations that require action.

When defining a relevant outcome indicator, it is useful to ask "what would success look like?" and "can this successful outcome be detected?" The answers to these questions will assist the enterprise in defining the specific target trying to be achieved.

A metric must be assigned to each indicator. The metric is the approach by which safety data will be compiled and reported in the SPI Program and determine whether the program provides the insight necessary to assess and act on safety issues. Insights on how to choose metrics is provided in the OECD Guidance.

\section{Step Four: Define Activities Indicator(s) and Related Metrics}

The next step is to define activities indicators to monitor the key elements of the safety programs, procedures, and policies identified in Step Two.

Activities indicators relate to outcome indicators and help to measure whether critical elements of safety programs, procedures, and policies are in place to achieve the desired outcomes. Whereas outcome indicators are designed to provide answers about whether you have achieved a safety outcome, activities indicators are designed to provide information about why or why not the outcome was achieved. Therefore, well-designed activities indicators should provide the information needed to correct programs, procedures, and policies when the desired outcome is not being achieved.

In identifying the appropriate activity indicators, the enterprise should consider those activities that are most important to achieving the intended target and most closely related to the outcome indicator(s) chosen in Step Three. If a change in the activity indicator does not result in a change of the outcome indicator, it may mean that the activity indicator is too far removed from the outcome indicator and a new activity indicator should be chosen. As with the outcome indicators, an appropriate measurement system needs to be established for the activities indicators.

\section{Step Five: Collect the Data and Report Indicator Results}

Once the outcome and activity indicators and metrics have been determined, the next step is to identify how to collect and report the results. The initial step is a review of existing data sources (e.g., information collected for quality control or other business purposes) to see what might be relevant and determine if they are of adequate quality to be used in the SPI Program.

Data collection procedures should address how frequently the data is to be collected and results reported. The data should be collected frequently enough to identify critical changes in the process in a timely manner so action can be taken to ensure safety at the facility. Reports should be provided in a 
Table 1. PI for management of change.

Outcome Indicators

(i) Extent technical modifications or other changes follow management of change procedures (or extent of noncompliance with management of change procedures).

(ii) Number of incidents resulting from failure to manage change appropriately (e.g., change in procedural process made without following the management of change policy).

(iii) Percentage of change requests that are processed as "emergency changes" (i.e., requiring immediate attention for safety reasons).

Activities Indicators

(i) Is there a clear definition of a change (modification)?

(ii) Are there procedures addressing the management of change, which cover all the necessary steps from planning to implementation and follow-up? Do the procedures address:

- approval by the relevant responsible person before proceeding to the next step;

- risk assessment, as appropriate;

- clear allocations of roles and responsibilities;

- a formal control form to steer and to keep track of the various steps in the procedure.

(iii) Do the procedures apply to technical changes as well as changes of organizational or administrative character? Do they address modifications in the following areas:

- technical, including changes in equipment and buildings (mechanical, instrumentation and control systems and other software, electrical, civil, etc.);

- process parameters and recipes, including raw material and chemicals, utilities, etc. (e.g., deviations from the approved "operating window");

- organization and management;

- personnel (manning, working times, outsourcing, etc.).

(iv) Do the procedures address permanent as well as temporary modifications (including pilot projects)?

(v) Do the procedures provide for a risk assessment and/or other appropriate review including prestartup review for relevant modifications? Does this address the need for competent personnel, independent from those directly responsible for the proposed change (recognizing that depending on the complexity and risk level, external expertise may be needed)?

(vi) Are there clear requirements related to the updating of technical and other documentation (e.g., do they require updating before a modification is implemented)?

(vii) Are there clear requirements for the updating of instructions/procedures and for information and training of employees before a modification is implemented?

timely manner to allow for appropriate actions to be taken. For indicators that use threshold metrics, the procedures should identify specific thresholds or tolerances, i.e., the point at which deviations in performance should be flagged for action.

\section{Step Six: Act on Findings from Safety Performance Indicators}

Results from SPIs, including tolerances being exceeded, disturbing trends over time, and inconsistent results, must be acted upon. Otherwise, there is little point in implementing an SPI Program. Timely reports with important information highlighted should be provided to senior managers, safety management personnel, engineers, operators, and other relevant employees. This information is paramount to ensuring quick follow-up action on adverse findings to fix problems in the associated processes, policies, and procedures.

\section{Step Seven: Evaluate and Refine Safety Performance Indicators}

The SPI Program, including the indicators and metrics, should be periodically reviewed and evaluated. These reviews help to ensure that the indicators are well-defined, continue to address priority areas of concern, and provide the information needed to monitor safety measures and to respond to potential safety issues. In addition, it will help to identify when specific indicators are no longer needed and allow adjustments to the SPI Program to focus on the most important issues and indicators.

\section{MENU OF SAFETY PERFORMANCE INDICATORS}

The OECD Guidance also contains examples of specific indicators addressing the various subjects that are important for chemical accident prevention, preparedness, or response. For example, SPI guidelines for the Management of Change are shown in Table 1.

\section{WHAT HAPPENS NEXT?}

The OECD and its member countries are pursuing three primary goals with respect to the SPI Guidance:

- distribution and promotion of the Guidance;

- translations; and

- development of an interactive website.

The OECD has distributed the Guidance to all OECD member countries, as well as to international organizations, industry and labor groups, and nongovernmental organizations. The documents are also 
available on the OECD website [3]. The OECD will be undertaking a number of additional activities to further promote the distribution and use of the Guidance.

As translations are completed, they will be made available on the OECD website.

Finally, the OECD, working with the US, is developing an interactive website for the Guidance. On this website, users will be able to access various topic areas and specific subjects as well as create a SPI Program specific to their organization. That website should be available in late 2009, and will be also be accessible at www.oecd.org/ehs.

\section{SUMMARY}

This article summarizes a more detailed description that is in the CCPS Symposium Proceedings [4]. The proceedings paper includes examples for each of the seven steps for creating an SPI program. Additional background for performance indicators are published by AICHE [5-7].

\section{LITERATURE CITED}

1. Guidance on Developing Safety Performance related to Chemical Accident Prevention, Prepared- ness, and Response, Organisation for Co-operation and Development, 2008, available at: http:// www.oecd.org/dataoecd/6/57/41269710.pdf.

2. Guiding Principles of Chemical Accident Prevention, Preparedness and Response, 2003, available at: http://www.oecd.org/dataoecd/60/39/ 21568440.pdf.

3. Chemical Accidents, OECD, available at: www.oecd.org/ehs.

4. K. Jennings and F. Schulberg, "The Organisation for Economic Co-operation and Development Guidance on Developing Safety Performance Indicators related to Chemical Accident Prevention, Preparedness and Response," CCPS Symposium Proceedings, 2009, pp. 168-185.

5. S. Arendt, Continuously improving PSM effectiveness-A practical roadmap, Process Saf Prog 25 (2006), 86-93.

6. J. Sweeney, Measuring process safety management, Plant/Oper Prog 11(1992), 89-98.

7. American Institute of Chemical Engineers, Process Safety Leading and Lagging Metrics, Center for Chemical Process Safety, American Institute of Chemical Engineers, New York, 2007. 